\title{
Glückwünsche des Leiters des Lehrstuhls für Aufbereitung und Veredlung an der Montanuniversität Leoben zum 80. Geburtstag von em. O. Univ.-Prof. Dr. mont. Hans Jörg Steiner
}

Verehrter akademischer Lehrer, geschätzter Emeritus, lieber Hans Jörg,

dass das Fachgebiet Aufbereitung und Veredlung innerhalb des Fächerkanons unserer Alma Mater Leobiensis eine derart bedeutende Stellung einnimmt, ist zu einem Gutteil deinem unermüdlichen Einsatz über fast vier Jahrzehnte als Ordinarius des Institutes für Aufbereitung und Veredlung an der Montanuniversität Leoben, dieser wunderbaren und einzigartigen Bildungsstätte im Herzen Leobens, zu verdanken. Dafür erlaube ich mir, dir im Namen der Leobener Aufbereiterinnen und Aufbereiter auf das Herzlichste zu danken.

Du hast dein ganzes berufliches Leben diesem herausfordernden Fach verschrieben und wurdest nicht müde, sowohl in der Lehre als auch in der Forschung Akzente zu setzen, die von Bestand sind. Die zu deinem 75. Geburtstag herausgegebene Festschrift Aufbereitung in Österreich II (ISBN 978-3-200-02738-1, 450 Seiten, Eigenverlag des Lehrstuh/s für Aufbereitung und Veredlung) legt eindrucksvoll Zeugnis von deiner Schaffenskraft und deinem tiefen Verständnis für die z.T. komplexen Vorgänge und wirkenden Kräfte in Aufbereitungsprozessen ab. Dass du zwischendurch in unseren Gesprächen bekennst, dass du immer wieder an Grenzen des Verstehens stößt, ehrt dich, ich glaube es dir nur nicht. Noch heute überraschst du mich bei der Bearbeitung gemeinsamer Projekte, wie du es schaffst, aus einer für mich aussichtslos erscheinenden geringen Datenlage wertvolle Informationen zu generieren und daraus auch noch prozessrelevante Erkenntnisse zu destillieren. Dass sich diese im Nachhinein als richtig herausstellen, brauche ich nicht zu betonen...

Danke auch für deine wohlwollende, stets respektvolle und freundschaftliche Begleitung durch die letzten Jahre. Es tut mir gut zu erkennen, dass du dich in unserer Aufbereiterfamilie nach wie vor wohlfühlst, dass du dich einbringst, an unserem Leben teilnimmst.

"Für eine gedeihliche Entwicklung der Jungen bedarf es des Segens der Alten". Das ist eine der Weisheiten, die in mir mittlerweile herangereift sind. Darum bitte ich dich, bleib uns weiterhin gewogen, schau bei uns vorbei, schau uns über die Schulter und reiche uns deine helfende Hand.
Im Namen der Leobener Aufbereiterfamilie wünsche ich dir von Herzen noch viele Jahre voller Gesundheit, Zufriedenheit und Freude.

Ein kräftiges Leobener Glückauf dem Jubilar, du lebest hoch!

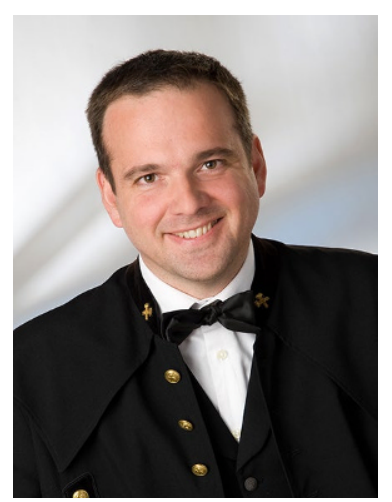

Univ.-Prof. Dr. mont. Helmut Flachberger im Namen der Leobener Aufbereiterinnen und Aufbereiter 